\title{
Readaptación de la era digital en el contexto educativo en tiempos de pandemia y postpandemia
}

La transformación digital ha sido un punto de agenda permanente a lo largo de años en todas las instituciones educativas, a pesar de los esfuerzos realizados sobre ello, en estos últimos tiempos los objetivos establecidos seguían siendo a mediano y largo plazo hasta que llego la pandemia, esta contingencia sanitaria causada por el Covid 19 , vino a dar un vuelco a la educación, con mayor énfasis en la pública, producto de ello los docentes y todos los miembros que conforman el equipo educativo, hoy día deben encontrar en las tecnologías un aliado para poder llevar a cabo el proceso de aprendizaje de una manera más efectiva y productiva.

Sobre lo anterior, se hace necesario, readaptar las clases a los entornos digitales de manera de minimizar la brecha que aún persiste para mantener el distanciamiento social y evitar aglomeraciones, entre las medidas de precaución exigidas por los entes encargados, todo esto de verdad que no ha sido tarea fácil para las instituciones educativas ni menos aún para docentes y estudiantes, entendiendo que aún no hay fecha exacta para el reintegro a las clases presenciales.

De la misma manera es importante destacar que ante ello se han tenido que adecuar las estrategias de enseñanza aprendizaje hacia un modelo de aprendizaje hibrido, entendiendo que ha tenido que haber un acercamiento hacia la comprensión del uso de las herramientas digitales, beneficiando así los debates, las prácticas educativas, los foros, las discusiones que si se quieren eran estrategias un tanto rezagadas por los docentes.

En el mismo orden de ideas, los docentes en su rol de formadores han tenido que dar un vuelco a su papel, entendiendo que han de convertirse en guías o facilitadores del aprendizaje para poder adquirir los conocimientos y sobre ellos poder multiplicarlos de una manera más asertiva que los pueda conllevar a obtener un aprendizaje verdaderamente significativo. 
Ante ello, las tecnologías de información y comunicación, ofrecen una gran oportunidad en estos tiempos, puesto que permiten la interacción entre los miembros de la comunidad educativa, además de poder establecer y crear líneas de trabajo tanto individuales como grupales y poder así desarrollar las competencias digitales de una manera más productiva, convirtiéndose hoy día en el único medio para poder educar. Es decir, en el proceso de adaptación han tenido que involucrarse todos para poder obtener los resultados esperados.

\section{Dra. Lenys OPiña-Jerrer}

lenyspina@iieakoinonia.org

Instituto de Investigación y Estudios Avanzados Koinonía

Venezuela

https://orcid.org/0000-0002-9493-7499 